\title{
Root and Shoot Traits of Spring Wheat Cultivars with Wild-Type and Semi- Dwarf Rht Alleles at Early and Late Growth Stages
}

\author{
Hayati Akman ${ }^{1, a, *}$, Philip Bruckner ${ }^{2, b}$ \\ ${ }^{I}$ Department of Plant and Animal Production, Selçuk University, 42430 Konya, Turkey \\ ${ }^{2}$ Department of Plant Sciences and Pathology, College of Agriculture, Montana State University, MT 59717, Bozeman, MT-USA
} ${ }^{*}$ Corresponding author

A R T I C L E IN F O A B S T R A C T

Research Article

Roots play an important role in improving crop yield by affecting the amount of water uptake and nutrient acquisition. The objective of this study was to characterize variability in root and aboveground characteristics among three diverse semi-dwarf spring wheat cultivars, 'Vida', 'Oneal' and 'Duclair' and a wild-type cultivar, 'Scholar' at early and late growth stages in a greenhouse. Plants

Received : 27/11/2020

Accepted : 12/02/2021 were grown in $45-\mathrm{cm}$ long tree pots in a greenhouse under optimal growth conditions. As soil-less media, a mixture of peat (70\%) and perlite (30\%) was used. Plants were harvested at tillering (GS2526) with 5-6 tillers, booting (GS43-45), and maturity (GS92). Root and shoot traits indicated significant variability among wild-type and semi-dwarf spring wheat cultivars at those growth stages. The study results showed that root mass per plant at tillering, booting, and maturity ranged from 0.10 to $0.14 \mathrm{~g}, 0.47$ to $0.9 \mathrm{~g}$, and 0.55 to $0.85 \mathrm{~g}$, respectively, while shoot mass per plant varied from 1.7 to $2.5 \mathrm{~g}, 6.5$ to $10.7 \mathrm{~g}$, and 21.2 to $24.5 \mathrm{~g}$, respectively. From booting to maturity, root mass was relatively constant, however, shoot mass increased considerably. Moreover, the average root mass of semi-dwarf spring wheat cultivars was $37 \%$ lower at booting and $30 \%$ lower at maturity compared to the wild-type cultivar, even though there was no significant variation among the cultivars at the early growth stage. Based on the results of the variability identified in this research, wild-type cultivar, Scholar can be evaluated for the improvement of genotypes with superior root system in breeding programs.

Wild-type

Semi-dwarf

Wheat cultivars

Root and shoot traits

Growth stage

|b@bruckner@montana.edu.tr

https://orcid.org/0000-0002-5936-8729

hayatiakman@selcuk.edu.tr (iD) https://orcid.org/0000-0001-6878-3329

This work is licensed under Creative Commons Attribution 4.0 International License

\section{Introduction}

Wheat (Triticum spp.) has been one of the most important staple crops in the world in terms of the global annual production of 734.1 million tons in 2018 (FAOSTAT, 2017). Wheat is currently grown in a wide range of environments from tropical to temperate.

The reduced height provides grain yield, contributing to allocate more an increase of assimilates into grain than straw (Evans, 2003; Griffiths et al., 2012), and conversely, plants having tall stem are sensitive to lodging. Rht-Blb and $R h t-D 1 b$ (formerly known as Rhtl and Rht2) genes have been widely considered to a reduction of the height and yield increase in wheat (Triticum aestivum L.) (Flintham et al., 1997; Pearce et al., 2011). However, these dwarfing genes may not be always beneficial for wheat improvement in drylands since they lead to a reduction in both coleoptile length and plant height (Na et al., 2009).

Roots provide nutrients and water to shoot and further anchor the plant to the soil. In limited input agricultural systems, root characteristics in relation to element uptake are often associated with yield (Atta et al., 2013; White et al., 2013; Heřmanská et al., 2015). However, root studies have been given less attention than easily accessible aboveground traits in breeding programs (Atta et al., 2013) since they are time-consuming, laborious, tedious, and efficient methods are unavailable (Robin et al., 2014). Despite the limitations of root studies, Lynch (2007) emphasized the root system as key in a potential second green revolution, therefore placing particular importance on selecting genotypes with superior root and grain yield combinations in breeding programs. Waines and Ehdaie (2007) showed genetic variation for root mass in semi-dwarf wheat. Furthermore, root mass has been considered to be one of the significant indicators of root system size by Ehdaie et al. (2010).

Exploring genetic variability of root and shoot traits contributing to grain yield could help the improvement of new cultivars with the desired root and shoot traits in wheat breeding programs. The objective of the study was to investigate root and shoot components of spring wheat cultivars in different backgrounds with variable semidwarfing alleles at early and late growth stages. 


\section{Materials and Methods}

This study was conducted at the Plant Growth Center of Montana State University. The greenhouse set points were $18.3-26.7^{\circ} \mathrm{C}$ day temperature and $18.3-23.9^{\circ} \mathrm{C}$ night temperature. A 16-hour photoperiod range with up to 3000 -foot candles of light was maintained in this greenhouse. Seedlings were planted into long pots $(45 \mathrm{~cm}$ deep, $19.5 \mathrm{~cm}$ width, and 9.63 liters in volume), which were filled by a soil-less mixture of Canadian Sphagnum peat moss and perlite blended in a 7:3 by volume ratio. Soil media was about $6.5 \mathrm{pH}$ and $1.5 \mathrm{ECe}(\mathrm{dS} / \mathrm{m})$ and was adequate for $\mathrm{PO}_{4}$ and $\mathrm{SO}_{4}$ and very low for $\mathrm{NH}_{4}$ and $\mathrm{Zn}$. $\mathrm{Mn}, \mathrm{Mg}, \mathrm{K}_{2} \mathrm{O}, \mathrm{P}_{2} \mathrm{O}_{5}, \mathrm{Cu}, \mathrm{Fe}, \mathrm{NO}_{3}$, and $\mathrm{B}$ were found low.

The study was arranged as a completely randomized design with three replications. Seeds were sown at the beginning of February. A single plant in each pot was grown. We used three semi-dwarf and one wild-type (tall) spring bread wheat cultivars. Vida and Duclair are Rhtl $(R h t-B 1 b)$ semi-dwarf cultivars. Oneal is a semi-dwarf wheat cultivar (unknown Rht genotype), and Scholar is a wildtype for Rhtl and Rht2 (Rht-Bla and Rht-Dla) alleles. Genotypes and their Rht knowledge were supplied from Montana Spring Wheat Breeding Program. Plants were grown in well-watered conditions. Standard agronomic practices were applied to provide nutrition and keep the plants free of diseases and pests.

All measurements were made on single plants grown individually in a pot. Roots were easily separated after a pre-soaking overnight in water before washing. Organic debris that remained on roots was removed by tweezers after manual washing. Washed and cleaned roots were then cut into $1-2 \mathrm{~cm}$ segments. Root and shoot dry weights were recorded after drying at $49^{\circ} \mathrm{C}$ for ten days. Dry root and shoot components were weighed, and tiller number and nodal roots were counted at the tillering stage (GS25-26; March 10), booting stage (GS43-45; March 27), and maturity (GS92; May 28). Furthermore, other significant agronomic traits including plant height, spike length, spikelets and kernels of the main spike, and grain yield per plant at maturity (Zadoks et al., 1974) were evaluated in the study. Statistical analysis was performed with the MSTAT-C statistic program and significant differences between means were tested by analysis of variance, followed by pairwise comparisons by Least Significant Difference (LSD) test (Russel, 1989).

\section{Results and Discussion}

The comparative experimental analysis revealed significant variations among the cultivars for root and shoot characteristics at tillering, booting, and maturity stages. Mean values for some important traits are shown in Figure 1 and 2.

There were no significant variations among wheat cultivars at the tillering stage in terms of the root mass, however, cultivars varied significantly at the booting and maturity stages (Figure 1a). The root mass of cultivars varied from 0.1 to $0.14 \mathrm{~g}$ at the tillering stage, 0.47 to $0.90 \mathrm{~g}$ at the booting stage, and 0.55 to $0.85 \mathrm{~g}$ at maturity (Figure 1a). The average root mass of semi-dwarf spring wheat cultivars was $37 \%$ lower at booting and 30\% lower at maturity compared to wild-type cultivar, Scholar (Figure 1a). Previous studies on root mass concerning wheat genotypes with different $R h t$ alleles were consistent with the results of our study. This finding supports the conclusions of Siddique et al. (1990) who found that semi-dwarf cultivars allocated less dry mass to their root than tall cultivars, leading to a lower root/shoot mass ratio. Subira et al. (2016) similarly reported that dwarfing alleles reduced root mass by $28 \%$ at anthesis. However, it was reported little or no effects on the wheat root system of $R h t$ alleles in field experiments (Cholick et al., 1977) and tube studies (Richards and Passioura, 1981). Moreover, a recent study indicated an increase in root mass in cultivars with Rht alleles (McCaig and Morgan, 1993).

In this study, root mass between seedling and booting increased substantially, then changed very little between booting and maturity. However, Gregory et al. (1978) and Barraclough and Leigh (1984) found that root was grown during tillering and stem elongation stages and reached maximum level at the flowering stage.

The mean nodal root number of these cultivars did not vary at tillering stage but showed cultivar variation at the late growth stages, booting, and maturity (Figure 1b). Nodal root number per plant varied from 12.3 to 18.7 at the tillering stage, 25.3 to 37.3 at booting then did not change much between booting and maturity except for the Oneal cultivar. Nonetheless, new nodal root formation was initiated after booting in some cultivars. Nodal roots are found in the topsoil (Ehdaie et al., 2010) and significant for increasing water and nutrient uptake in seasonal rainfall conditions (Wasson et al., 2012).

Significant increase in shoot mass occurred between the booting and maturity stages. The shoot mass of spring wheat cultivars was in a range of 1.7 to $2.5 \mathrm{~g}$ at the tillering stage, 6.5 to $10.7 \mathrm{~g}$ at booting, and 21.2 to $25.3 \mathrm{~g}$ at maturity. In the study, Scholar, the wild-type cultivar had significantly greater shoot mass than the semi-dwarf cultivars at the booting and maturity stages. The shoot mass did not vary among semi-dwarf cultivars. Results here are consistent with the findings of Subira et al. (2016) showing that $R h t B 1 b$ semi-dwarf allele reduced shoot mass up to $7.6 \%$ at anthesis.

The increase in root mass may have contributed to the increase in shoot mass due to captured resources, similarly, the increase in shoot mass may lead to allocate assimilates to root growth (Narayanan et al., 2014). In the present research, wild-type cultivar, Scholar had the greatest root and shoot mass compared to semi-dwarf cultivars as a result of possibly combined effect in root and shoot growth, supporting the growth of each other.

The tiller number of spring wheat was 4.7 to 6 at the tillering stage and 9.7 to 14 at the maturity, though there were no significant variations among the spring wheat cultivars (Figure 1d). The fertile tiller number was lower than the total tiller number with 8 to 11.7 at maturity (Figure 1d). Fertile tiller number as a proportion of the total tiller number was the lowest for Scholar and the highest for Duclair which had the same total tiller and fertile tiller counts. Tiller number/nodal root number ratios were 2.9 at the tillering stage and 3.5 at maturity. This result supported a previous study indicating that especially secondary tillers dying prematurely had an adverse effect on nodal roots (Anderson-Taylor and Marshall, 1983). Also, Narayanan et 
al. (2014) indicated highly significant and positive relationships in 297 spring wheat genotypes between tiller number with rooting depth, root mass and shoot mass.

In the study, the plant height of cultivars ranged from 65.4 to $78.1 \mathrm{~cm}$ at maturity (Figure 2). The wild-type cultivar, Scholar was taller than the three semi-dwarf spring wheat cultivars (Figure 2). Rht-Blb and $R h t-D l b$ alleles affecting reduction in plant height are included in 95\% of modern wheat cultivars in the world (Hedden, 2003). Rht-Blb and Rht-Dlb reduced plant height up to $20.5 \%$ and $22.4 \%$ and increased yield up to $6.1 \%$ and $14.1 \%$, respectively (Robbins, 2009). Results of this investigation ware similar to the findings of Ellis et al.
(2002), Na et al. (2009), Liatukas and Ruzgas (2011) who reported that cultivars containing $R h t-B 1 b$ and $R h t D 1 b$ ware shorter than cultivars without $R h t$ alleles.

As shown in Figure 2, agronomic characteristics including spike length, spikelets, kernel weight and kernels for main spike and yield per plant measured in the greenhouse under optimized conditions were variable among cultivars. The study showed that Vida had lower results per the main spike, while it possessed the highest grain yield per plant. Besides, semi-dwarf cultivar, Oneal had the lowest yield per plant, but wild-type cultivar, Scholar involved in the same group with semi-dwarf cultivars about yield per plant.
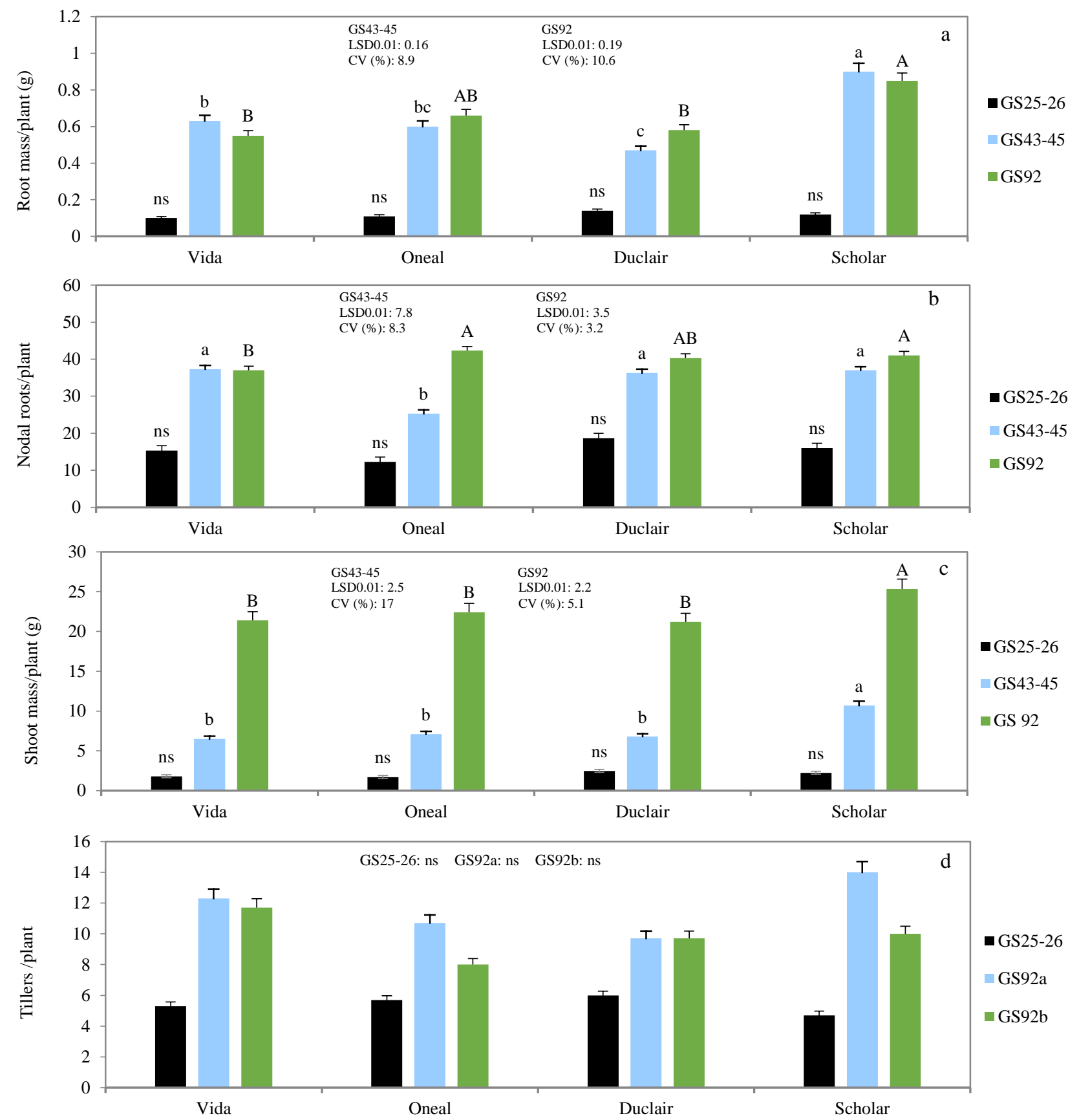

Figure 1. a, b and c represent nodal root number, root mass and shoot mass for the plant of wild-type cultivar (Scholar) and semi-dwarf wheat cultivars (Vida, Oneal and Duclair) at tillering (GS25-26), booting (GS43-45) and maturity (GS92), respectively. Fig.1d indicates tillers/plant. In addition to this, GS92a shows total tillers per plant at maturity, while GS92b is fertile tillers per plant at maturity. LSD indicates least significant difference and CV for coefficient of variation 

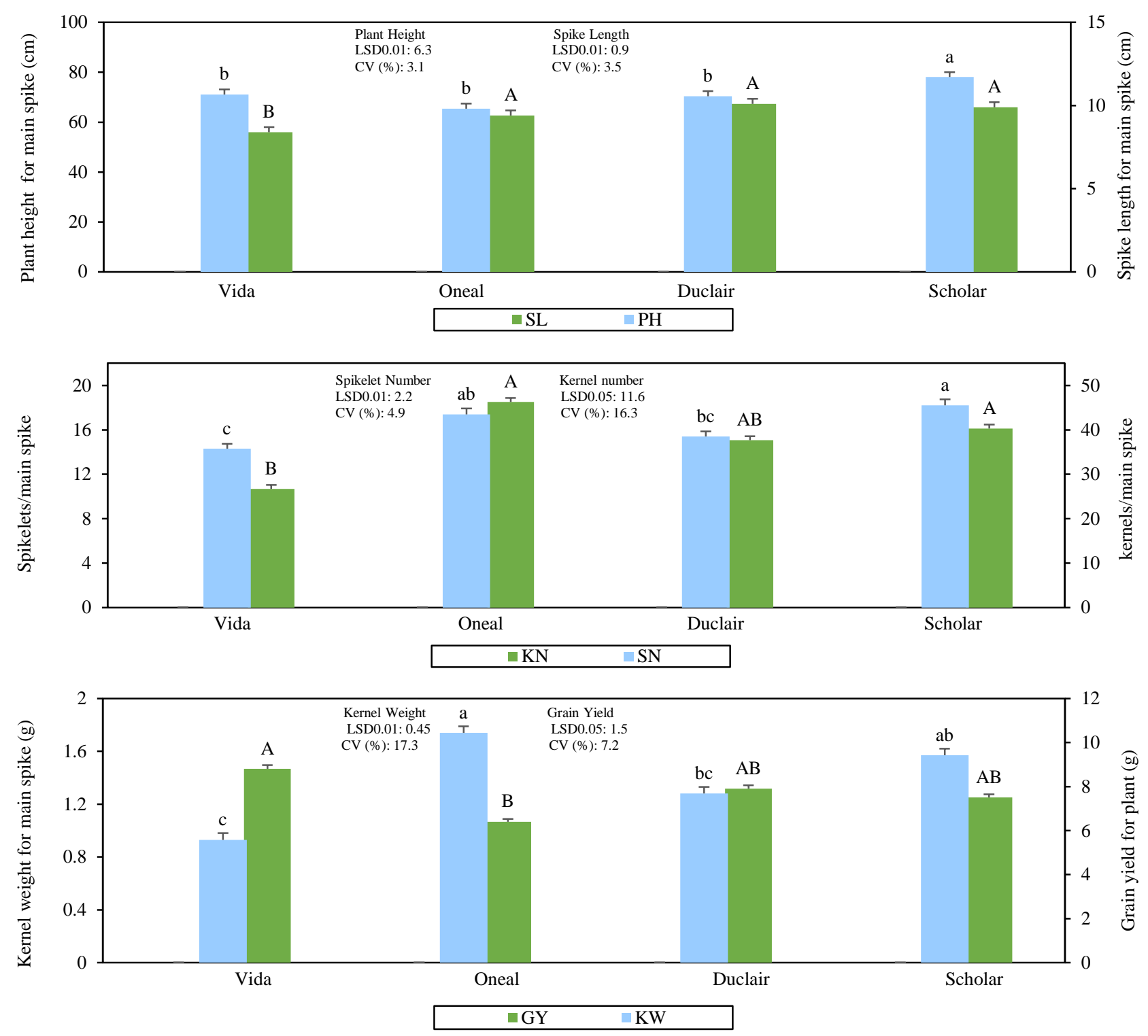

Figure 2. Plant height (PH), spike length (SL) spikelet number (SN), kernel number (KN) and kernel weight (KW) in main spike as well as grain yield (GY) per plant of spring wheat cultivars at maturity. LSD indicates least significant difference and $\mathrm{CV}$ for coefficient of variation

Roots have great importance for achieving potential yield in wheat cultivars, particularly under rain-fed conditions. The experiments performed here clearly demonstrated that there were no significant variations between semi-dwarf cultivars and the wild-type cultivar at the tillering stage in terms of root mass, shoot mass, and nodal roots per plant. However, significant variations between semi-dwarf cultivars and the wild-type cultivar for root and shoot mass were observed at the booting and maturity. Compared with wild type cultivar, semi-dwarf spring wheat cultivars had the lower root and shoot mass. Our comparative experimental approach suggested that the wild-type cultivar, Scholar can be used to improve new cultivars with higher root mass in wheat improvement programs.

\section{Acknowledgments}

The authors are grateful to the Turkish Council of Higher Education to support for study abroad. We would like to thank Prof. Luther Talbert to supply his spring cultivars.

\section{References}

Anderson-Taylor G, Marshall C. 1983. Root-tiller interrelationships in spring barley (Hordeum distichum (L.) Lam.). Annals of Botany, 51: 47-58. Doi: 10.1093/ oxfordjournals.aob.a086449

Atta BM, Mahmood T, Trethowan RM. 2013. Relationship between root morphology and grain yield of wheat in NorthWestern NSW. Australia. Aust. J. Crop Sci., 7: 2108-2115.

Barraclough PB, Leigh RA. 1984. The growth and activity of winter wheat roots in the field: the effect of sowing date and soil type on root growth of high-yielding crops. The Journal of Agricultural Science, 103: 59-74. Doi: 10.1017/ S002185960004332x

Cholick FA, Welsh JR, Cole CV. 1977. Rooting patterns of semidwarf and tall winter wheat cultivars under dryland field conditions. Crop Science, 17: 637-640. Doi: 10.2135/ cropsci1977.0011183X001700040040x

Ehdaie B, Merhaut DJ, Ahmadian S, Hoops AC, Khuong T, Layne AP, Waines JG. 2010. Root system size influences water-nutrient uptake and nitrate leaching potential in wheat. J. Agro. Crop Sci., 196: 455-466. Doi: 10.1111/j.1439037X.2010.00433.x 
Ellis M, Spielmeyer W, Gale K, Rebetzke G, Richards R. 2002. "Perfect" markers for the Rht-Blb and Rht-Dlb dwarfing genes in wheat. Theoretical and Applied Genetics, 105: 10381042. Doi: 10.1007/s00122-002-1048-4

Evans LT. 2003. Crop Evolution, Adaptation, and Yield. 1st ed. Cambridge, Great Britain: Cambridge University Press.

Flintham JE, Börner A, Worland AJ, Gale MD. 1997. Optimizing wheat grain yield: effects of $R h t$ (gibberellin-insensitive) dwarfing genes. The Journal of Agricultural Science, 128: 1125. Doi: $10.1017 /$ S0021859696003942

Food and Agriculture Organization (FAO). 2018. FAOSTAT Statistical Database of the United Nation Food and Agriculture Organization (FAO) Statistical Division. Rome. Available at: http://www.fao.org/faostat/en/\#data/QC, Accessed December, 2020.

Gregory PJ, McGowan M, Biscoe PV, Hunter B. 1978. Water relations of winter wheat: 1 . growth of the root system. The Journal of Agricultural Science, 91: 91-102. Doi: $10.1017 /$ S0021859600056653

Griffiths S, Simmonds J, Leverington M, Wang Y, Fish L, Sayers L, Alibert L, Orford S, Wingen L, Snape J. 2012. Meta-QTL analysis of the genetic control of crop height in elite European winter wheat germplasm. Mol. Breeding, 29: 159-171. Doi: 10.1007/s11032-010-9534-x

Hedden P. 2003. The Genes of the green revolution. Trends Genet., 19: 5-9. Doi. 10.1016/S0168-9525(02)00009-4

Heřmanská A, Středa T, Chloupek O. 2015. Improved wheat grain yield by a new method of root selection. Agron. Sustain. Dev., 35: 195-202. Doi. 10.1007/s13593-014-0227-4

Liatukas Z, Ruzgas V. 2011. Coleoptile length and plant height of modern tall and semi-dwarf European winter wheat cultivars. Acta Societatis Botanicorum Poloniae, 80: 197 203. Doi: $10.5586 / a s b p .2011 .018$

Lynch JP. 2007. Roots of the second green revolution. Australian Journal of Botany, 55: 493-512. Doi: 10.1071/BT06118

McCaig TN, Morgan JA. 1993. Root and shoot dry matter partitioning in near-isogenic wheat lines differing in height. Canadian Journal of Plant Science, 73: 679-689. Doi: 10.4141/cjps93-089

Na T, Jiang Y, He BR, Hu YG. 2009. The effects of dwarfing genes (Rht-B1b, Rht-D1b, and Rht8) with different sensitivity to GA3 on the coleoptile length and plant height of wheat. Agricultural Sciences in China, 8: 1028-1038. Doi: 10.1016/S1671-2927(08)60310-7
Narayanan S, Mohan A, Gill KS, Prasad PV. 2014. Variability of root traits in spring wheat germplasm. Plos One, 9: 1-15. Doi: 10.1371/journal.pone. 0100317

Pearce S, Saville R, Vaughan SP, Chandler PM, Wilhelm EP, Sparks CA, Hedden P. 2011. Molecular characterization of Rht-1 dwarfing genes in hexaploid wheat (Triticum aestivum). Plant Physiology, 157: 1820-1831. Doi: 10.1104/pp.111.183657

Richards RA, Passioura JB 1981. Seminal root morphology and water use of wheat I. environmental effects 1 . Crop Science, 21: 249-252. Doi: 10.2135/cropsci1981.0011183 X002100020011x

Robin AHK, Uddin MJ, Afrin S, Paul PR. 2014. Genotypic variations in root traits of wheat cultivars at phytomer level. J. Bangladesh Agric., 12: 45-54. Doi: 10.3329/ jbau.v12i1.21238

Robbins AM. 2009. Dwarfing Genes in Spring Wheat: and Agronomic Comparison of Rht-B1, Rht-D1, and Rht8 Doctoral dissertation, Montana State University-Bozeman, College of Agriculture.

Russel DF. 1989. MSTAT-C Statistical package program ver. 2.1. Michigan State University.

Siddique HM, Belford RK, Tennant D. 1990. Root: shoot ratios of old and modern, tall and semi-dwarf wheats in a mediterranean environment. Plant and Soil, 121: 89-98.

Subira J, Ammar K, Álvaro F, Del Moral LFG, Dreisigacker S, Royo C. 2016. Changes in durum wheat root and aerial biomass caused by the introduction of the Rht-Blb dwarfing allele and their effects on yield formation. Plant and Soil, 403: 291-304. Doi: 10.1007/s11104-015-2781-1

Waines J, Ehdaie B. 2007. Domestication and Crop Physiology: Roots of Green-Revolution Wheat. Ann. Bot., 100: 991-998. Doi: $10.1093 / \mathrm{aob} / \mathrm{mcm} 180$

Wasson AP, Richards RA, Chatrath R, Misra SC, Prasad SVS, Rebetzke GJ, Kirkegaard JA, Christopher J, Watt M. 2012. Traits and selection strategies to improve root systems and water uptake in water-limited wheat crops. J. Exp. Bot., 63: 3485-3498. Doi: 10.1093/jxb/ers111

White PJ, George TS, Gregory PJ, Bengough AG, Hallett PD, McKenzie BM. 2013. Matching roots to their environment. Ann. Bot., 112: 207-222. Doi: 10.1093/aob/mct123

Zadoks JC, Chang TT, Konzak CF. 1974. A decimal code for the growth stages of cereals. Weed Research, 14: 415-421. 